\title{
ВмJ Global Health Confronting power in low places: historical analysis of medical dominance and role-boundary negotiation between health professions in Nigeria
}

\author{
Okikiolu Badejo (D) , ${ }^{1}$ Helen Sagay (D) , ${ }^{2}$ Seye Abimbola (D) , Sara Van Belle (1) ${ }^{1}$
}

To cite: Badejo 0, Sagay H, Abimbola S, et al. Confronting power in low places: historical analysis of medical dominance and role-boundary negotiation between health professions in Nigeria. BMJ Global Health 2020;5:e003349. doi:10.1136/ bmjgh-2020-003349

Handling editor Valery Ridde

- Additional material is published online only. To view, please visit the journal online (http://dx.doi.org/10.1136/ bmjgh-2020-003349).

The ideas in this paper were presented in the Emerging Voices for Global Health (EV4GH) Program at the 5th Global Symposium on Health Systems Research, Liverpool 2018.

Received 4 July 2020 Revised 13 August 2020 Accepted 28 August 2020

Check for updates

\section{(c) Author(s) (or their} employer(s)) 2020. Re-use permitted under CC BY-NC. No commercial re-use. See rights and permissions. Published by BMJ.

For numbered affiliations see end of article.

Correspondence to Dr Okikiolu Badejo; okikolubadejo@gmail.com

\section{ABSTRACT}

Introduction Interprofessional interaction is intrinsic to health service delivery and forms the basis of task-shifting and task-sharing policies to address human resources for health challenges. But while interprofessional interaction can be collaborative, professional hierarchies and discipline-specific patterns of socialisation can result in unhealthy rivalry and conflicts which disrupt health system functioning. A better understanding of interprofessional dynamics is necessary to avoid such negative consequences. We, therefore, conducted a historical analysis of interprofessional interactions and role-boundary negotiations between health professions in Nigeria. Methods We conducted a review of both published and grey literature to provide historical accounts and enable policy tracing of reforms related to interprofessional interactions. We used Nancarrow and Borthwick's typology for thematic analysis and used medical dominance and negotiated order theories to offer explanations of the conditions that facilitated or constrained interprofessional collaboration.

Results Despite an overall context of medical dominance, we found evidence of professional power changes (dynamics) and role-boundary shifts between health professions. These shifts occurred in different directions, but shifts between professions that are at different power gradients were more likely to be non-negotiable or conflictual. Conditions that facilitated consensual roleboundary shifts included the feasibility of simultaneous upward expansion of roles for all professions and the extent to which the delegating profession was in charge of role delegation. While the introduction of new medical diagnostic technology opened up occupational vacancies which facilitated consensual role-boundary change in some cases, it constrained professional collaboration in others.

Conclusions Health workforce governance can contribute to better functioning of health systems and voiding dysfunctional interprofessional relations if the human resource for health interventions are informed by contextual understanding (informed by comparative institutional and health systems research) of conditions that facilitate or constrain effective interprofessional collaboration.

\section{Key questions}

What is already known?

- Interprofessional collaboration is an important prerequisite for interventions addressing human resource challenges.

- Power dynamics and role-boundary shifts between health professions have important implications for health systems functioning.

What are the new findings?

- Facilitators of consensual power change and roleboundary shifts include the feasibility of simultaneous upward expansion of roles for all professions and when the delegating profession was in charge of the extent of role delegation.

- Introduction of new technology can work both ways by either facilitating or constraining consensual role-boundary changes and interprofessional collaboration.

What do the new findings imply?

- Our findings suggest that health workforce governance can contribute to better functioning of health systems if informed by a contextual understanding of conditions that facilitate or constrain effective interprofessional collaboration.

- To do this, research will have to shift from a focus on political powers in high places, and instead (or in addition) concentrate on efforts to help health systems navigate the swampy lowland of professional rivalry and power.

\section{INTRODUCTION}

Health workforce governance has been a continuous preoccupation of efforts aimed at health systems strengthening globally. However, health workforce governance has gained even more relevance in the face of gross shortages of qualified health workers or, in some settings, an oversupply of unqualified health workers. ${ }^{1}{ }^{2}$ In high-income countries (HICs), health workforce reforms were 
implemented from the 1990s as part of wider reforms to reorganise health services through such initiatives as New Public Management in healthcare in the UK and managed competition reforms in Australia and the Netherlands. ${ }^{3-5}$ Such reforms had an impact on interprofessional relations within the healthcare sector, in some instances leading to the weakening of the corporatist power of some professions, the emergence or alliance of others, and, in other instances, hybrid configurations of health workforce governance. ${ }^{4-12}$ In low-income and middle-income countries (LMICs), policy convergence on health workforce reforms centred around promoting workforce flexibility and task-shifting ${ }^{13-15}$ as a major component of efforts to address workforce challenges for priority health issues like HIV, non-communicable diseases and essential surgery. ${ }^{16-19}$

The workforce flexibility agenda is usually underpinned by moves to unbind roles from professional boundaries and 'rationally re-distribute' roles in a way that can make the most efficient use of scarce resources and as a way to address rural health workforce retention. ${ }^{20}$ Although contest over professional boundaries and the relative importance of the different health professions has always been an issue in healthcare, ${ }^{21-23}$ it is within this context of calls for increased flexibility that interprofessional tensions come to the forefront. Under these circumstances, factors like professional hierarchies and discipline-specific patterns of socialisation undermine health reforms and interventions that rely on effective interprofessional collaboration. For example, severe disruptions to health service delivery have been reported in Nigeria and Kenya since early 2000 due to interprofessional conflicts. ${ }^{2425}$ This rivalry is more apparent in countries where the management of health services rely on health professionals themselves rather than on specialist managers, which effectively extends the scope of interprofessional rivalry from service delivery to the managerial domain. ${ }^{26}$

Avoiding the negative consequences to health systems governance requires a better (contextualised and pathdependent) understanding of how interprofessional dynamics in specific settings have evolved and the conditions which facilitate or constrain interprofessional collaboration. Our study will address these concerns but first briefly elaborate on relevant important theories that have shaped understanding in this regard.

\section{Theories and concepts of professional interaction in health}

Medical dominance theory and the theory of negotiated order have been used to explore interprofessional interactions in healthcare. ${ }^{27-29}$ The central idea of the medical dominance theory developed mainly by Freidson (1970) and Ovretveit (1985) is that medicine occupies a peak position in the hierarchy of professions that make up the health service division of labour, and as a result exercises autonomy over its work and also over that of other health professions. Although political, social, organisational and technological changes over time have challenged the extent, form or nature of this dominance, the medical profession has quite successfully navigated these challenges. ${ }^{30-32}$ Influential at the time, medical dominance theory no longer sufficiently captures the current, increasingly complex, differentiated and dynamic nature of interprofessional relationships, which require a shift away from a focus on respective gain or loss of professional power to what professional power and knowledge entail and how it is transformed. ${ }^{33-36}$

Roughly from the same period, the theory of negotiated order developed by Anselm Strauss (1978, 1994) focuses on the social interactions between professions which constitute a 'negotiated' social 'order' or structure. ${ }^{37}$ The hierarchy between professions is thus not a given, but under continuous negotiation in the social order of professions. Professional status is thus socially constructed and interprofessional relationships are mediated through a process of negotiation between two distinct social groups. Negotiation here is defined as a means of 'getting things accomplished'. The theory emphasises the nuanced, diverse and distributed characteristics of power, as being complex with multiple origins, in and outside the healthcare context, rather than the static and unidirectional focus of the medical dominance theory. The negotiated order theory has also been extended to mean that interprofessional competition is a fundamental act of professional life and that professional groups are constantly engaged in a battle over work jurisdictions and role boundaries.

Using theories from the field of interprofessional care, Nancarrow and Borthwick more recently (2005) described four directions in which role boundaries within the health workforce change: vertical substitution, horizontal substitution, specialisation and diversification. ${ }^{38}$ Vertical substitution between professions refers to the transference of tasks across different health professions that are not equivalent in terms of training, expertise, power or autonomy. Horizontal substitution occurs when health providers with a similar level of training and expertise, but from different disciplinary backgrounds, undertake roles that are normally the domain of another discipline. Specialisation refers to the "adoption of an increasing level of training and expertise in a specific disciplinary area that is adopted by a select group of the profession and legitimised through the use of a specific title, membership to a closed subgroup of the profession". Diversification refers to the identification of a novel approach to practice that has previously not been 'owned' by a particular disciplinary group, resulting in the expansion of the role for that discipline. This typology captures the current dynamic nature of professional boundaries and inter-relationships, as shown in figure 1.

Although many studies have drawn on these theories to examine interprofessional interactions in health, most have been in HICs. Few studies have explored interprofessional interactions in LMIC and most of these studies focus on health worker perspectives on interprofessional conflicts. While they offer useful first-hand accounts of 


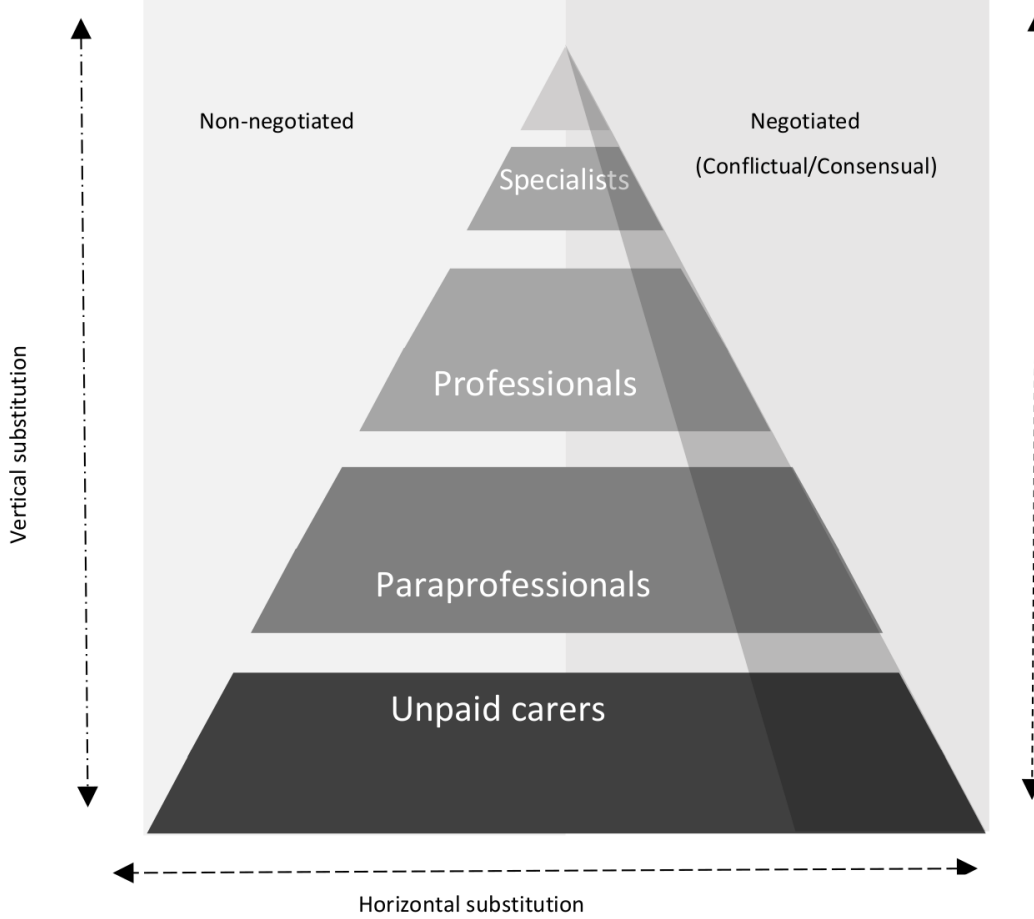

Horizontal substitution

More likely in workers with similar roles. No change in power, status or income Influenced by situational factors - staff shortages, settings of care
High professional security (little risk of substitution) High autonomy High rewards

Highly regulated High risk resources High risk procedures High cost to train

Greater ownership of technology

Figure 1 Power pyramid of professions in healthcare and direction for role-boundary changes. Vertical substitution is possible in any vertical direction, horizontal substitution is possible between professions at equal level on the power gradient. Both types of shifts can both be consensual or conflictual. Adapted from Nancarrow and Borthwick. ${ }^{38}$

health workers' views of their collaborative work, such studies are limited in their ability to account for the full range of relational, organisational and contextual factors that shape interprofessional interactions. Moreover, those studies do not provide sufficiently theorised accounts of their findings and as a result, lack sufficient theoretical explanation which can enhance understanding to inform theory and practice across settings.

Using Nigeria as a case study, this study aims to document the evolving nature of interprofessional interaction in health and draw on relevant theories to illuminate the nature of these interactions and conditions that facilitate or constrain interprofessional collaboration.

\section{Historical evolution of health professions and health services in Nigeria}

Formal health services in Nigeria have deep historical roots in the British colonial legacy of health service organisation. ${ }^{39}$ Nigeria inherited colonial hospital models of care which established a hierarchical system of health professions that had medicine at the top, with other professions performing subordinate roles to support service delivery. ${ }^{40}$ Some factors consolidated this domination, most notable being the establishment and recognition of self-regulating professional medical associations, the Nigerian Medical Association (in 1960) and the Nigerian Medical Council (in 1963) shortly after independence from British colonial rule in $1960 .{ }^{41}{ }^{42}$ As the earliest statutory regulatory health organs, their powerful political influence positioned the medical profession as gatekeepers with the jurisdiction to control the scope and practice of the other, less evolved and organised, health professions. ${ }^{43}$

Compared with medicine, the nursing profession in Nigeria evolved more slowly despite a slightly longer history as a self-regulating profession-the Nursing Council of Nigeria was formed in $1947 .{ }^{44}$ Nevertheless, the nursing profession also became politically skilful enough to enjoy considerable autonomy within Nigeria's health workforce, using strategies similar to that of the medical profession. Together, these strategies refer to the concept of 'occupational closure', by which occupations use regulation or licensure to secure or consolidate jurisdictions of work. Given their historical head-start, medicine and nursing could be seen as the central health professions in Nigeria, and have for the most part influenced policy framing, formulation and implementation. Similar strategies were, although much later on, being employed by other health professions. The Pharmacists Council of Nigeria was established in 1992, while the Medical Laboratory Science Council of Nigeria was established in $2004 .^{45} 46$

Human resources for health governance is overseen by the Federal Ministry of Health whose primary functions include central policy development and health-sector coordination. At sub-national levels, human resource for health governance occurs through clinical-administrative 
decision-making at different levels of governance. At each level, health sector functions are overseen by the medical profession, both clinically and managerially, with medical hierarchy existing alongside subordinate health professionals and administrative staff. ${ }^{43}$ Although all health professions have individual hierarchies supervised by individual profession-head, they formally report to a medical director (typically a doctor) with clinical and administrative duties. This arrangement is considered the norm and is reflected in the headship of health ministries and agencies.

\section{METHODS}

We conducted a historical analysis of how interprofessional interactions have evolved among health professions in Nigeria, and with this knowledge identify conditions under which professional collaboration can be better enhanced. The use of a systematic review of the literature was precluded by the absence of structured data repositories for the various documents that were instrumental to our analyses. We, therefore, relied on a multilevel search strategy that combined scoping review of scholarly publications with a desk review of relevant documents retrieved from various official sources and professional associations. To achieve this, we followed Arksey and O'Malley's ${ }^{48} 5$-step framework for conducting scoping reviews:

\section{Conceptualisation of key terms}

To guide our data search and data collection, it was important to clarify the key concepts of our research question.

\section{Power}

Following Friedson, we used the notion of professional power to refer to the ability of professions to control the content and condition of their work (autonomy) and the work of other professions (authority) ${ }^{49}$ For our study, we looked for sets of activities and tactics that health professions in Nigeria have used to achieve authority and autonomy.

\section{Medical dominance}

We use medical dominance to describe the relation of the medical profession to other health professions, in the degree to which it has exercised its authority and autonomy within the Nigerian healthcare division of labour. $^{32} 49$

\section{Role-boundary negotiation}

We use negotiation to refer to the continuous tactics used by professions to establish, maintain, redefine or renew the roles and boundaries concerning the tasks they perform, including what boundary roles can be negotiated and how. Professional boundaries here refer to the link between a profession and the work it performs. ${ }^{36} 3750$

\section{Identifying relevant studies and other sources of information}

The next step in our multilevel search strategy was to extract relevant data from governmental policies and legislation that touches on interprofessional relations. We took information directly from their original document sources without applying a time limit, as our goal was to construct a historical timeline of events. We excluded documents written in languages other than English and also excluded documents developed by non-governmental organisations. Documents retrieved include official reports, policies and guidelines from government Ministries, Department and Agencies (MDAs), official reports of the Presidential Committee of Experts on Professional Relationships in the public health sector, legislative documents (Acts of Parliament setting up regulatory functions of MDAs, different professional associations and the Teaching Hospitals Act) and court order rulings adjudicating interprofessional conflicts. Other non-confidential official documents retrieved from MDAs and professional health associations include communiques, meeting minutes, memoranda, health sector review reports, health sector programme of work and national strategic plans.

Next, we conducted a search of academic databases for scholarly publications on medical dominance and interprofessional relations in Nigeria. We searched electronic databases (PubMed, Google Scholar) using a combination of Boolean search terms. Words included in our search are found in table 1. Also, we searched local journals and reference lists of selected studies and also contacted some authors of related publications for further clarifications.

In the fourth step, we merged both documents and articles retrieved from literature databases and desk reviews into a single document repository for our review.

Our purposive choice of Nigeria was based on experience and exposure of the authors to the focus of analysis. OB, HS and SA received medical training in Nigeria and at different times worked as frontline health workers, programme managers and researchers within Nigeria's health and development sector. This allowed the authors to draw on more than a decade of experience from observing and taking part in health worker strikes, popular and media debates on interprofessional rivalry on social media (Twitter, Facebook, LinkedIn) and the Nigerian press, as well as observing how interprofessional tensions have played out in the wider social sphere.

The multi-level search strategy is presented in table 2 .

\section{Study selection}

Application of the search terms during the literature database search yielded 191 entries from PubMed and Google Scholar (table 1). Two authors (OB and HS) applied inclusion and exclusion criteria (based on our key concepts) on the title and abstract sections of each article after which the number of articles reduced to 40. After reading the full text of the remaining papers, a further 15 papers were excluded based on 


\begin{tabular}{|c|c|c|}
\hline Number & Searches & Hits \\
\hline \#5 & Search \#1 AND \#2 AND \#3 AND \#4 Sort by: Relevance Filters: English & 191 \\
\hline \#4 & Nigeria & 53184 \\
\hline \#3 & $\begin{array}{l}\text { workforce OR Human resource for health OR health professional OR physician OR non-physician OR } \\
\text { health service provider OR (Health personnel(mh] OR nurse(tiab] OR nurses(tiab] OR physician(tiab] } \\
\text { OR physicians(tiab] OR health provider(tiab] OR health providers(tiab] OR health care provider(tiab] } \\
\text { OR health care providers(tiab] OR healthcare provider(tiab] OR healthcare providers(tiab] OR health } \\
\text { worker(tiab] OR health workers(tiab] OR midwife(tiab] OR midwives(tiab] OR health care worker(tiab] } \\
\text { OR health care workers(tiab] OR healthcare worker(tiab] OR healthcare workers(tiab] OR community } \\
\text { health worker(tiab] OR community health workers(tiab] OR practitioner(tiab] OR practitioners(tiab] OR } \\
\text { clinician(tiab] OR clinicians(tiab] OR doctor(tiab] OR doctors(tiab] OR clinical officer(tiab] OR clinical } \\
\text { officers(tiab] OR medical personnel(tiab] OR health professional(tiab] OR health professionals(tiab] OR } \\
\text { frontline provider(tiab] OR frontline providers(tiab] OR frontline worker(tiab] OR frontline workers(tiab] } \\
\text { OR traditional birth attend*(tiab] OR front line provider*(tiab] OR front line worker*(tiab)) }\end{array}$ & 2004585 \\
\hline \#2 & $\begin{array}{l}\text { health governance OR health services administration OR health regulation OR health authority } \\
\text { OR healthcare management OR health systems governance OR health leadership OR health } \\
\text { administration OR health agencies OR clinical governance }\end{array}$ & 4336238 \\
\hline$\# 1$ & $\begin{array}{l}\text { (negotiation OR rivalry OR conflict resolution OR harmony OR strikes OR health worker strikes OR } \\
\text { health crises) OR (medical dominance OR dominance OR hierarchy OR subordination) }\end{array}$ & 1387681 \\
\hline
\end{tabular}

the judgement of the reviewers (OB and HS) on their relevance.

As our study greatly relied on varied non-scholarly document sources to construct a historical sequence of interprofessional relations, it was important to examine all information to determine truthfulness, bias, omissions and consistency in data. We attempted to do this using Scott's four criteria for assessing documentary sources in social research. ${ }^{51}$ We first considered the authenticity of documents, which refer to whether the evidence is genuine and of unquestionable origin. Second, we

Table 2 Multilevel search strategy

\begin{tabular}{ll}
\hline Data source & Approach \\
\hline $\begin{array}{l}\text { Literature search/ } \\
\text { publications }\end{array}$ & $\begin{array}{l}\text { Review of relevant journal } \\
\text { publications on medical dominance, } \\
\text { role-boundary changes, health } \\
\text { professional rivalry in Nigeria }\end{array}$ \\
Desk review & $\begin{array}{l}\text { Review of documents from } \\
\text { government MDAs and professional } \\
\text { health associations }\end{array}$ \\
Media review & $\begin{array}{l}\text { Review of comments and social } \\
\text { debates among stakeholders in } \\
\text { Nigerian newspapers, augmented by } \\
\text { wider social debates on social media } \\
\text { platforms } \\
\text { Experience and exposure to the } \\
\text { focus of analysis. OB, HS, and SA } \\
\text { received medical training in Nigeria } \\
\text { and at different times worked as } \\
\text { frontline health workers, programme } \\
\text { managers and researchers within } \\
\text { Nigeria's health and development } \\
\text { sector }\end{array}$ \\
\hline
\end{tabular}

MDA, Ministries, Department and Agencies. screened for credibility, which refers to if the information is free from error and distortion. Third, we checked for representativeness, which assesses whether the evidence is typical of its kind, and, if not, whether the extent of its untypicality is known. Finally, we checked for meaning, which assesses whether the evidence is clear and comprehensible. Two authors (OB and HS) independently performed this assessment by adapting the AACODS tool for evaluation and critical appraisal of grey literature. $^{52}$ The AACODS checklist covers six key constructs (authority, accuracy, coverage, objectivity, date, significance), five of which were deemed relevant and therefore recoded into the four categories proposed by Scotts. For each of the four criteria, a score of 0 was given if a document did not meet the criteria or if information was unavailable, and a score of 5 if the criteria were met, totalling 20 points. Any document scoring less than 10 (half of the possible total) on the adapted checklist was not considered. Uncertainty or differences regarding the score of reviewed documents was resolved through discussion between the authors. Details of the adapted checklist and scoring are presented in online supplemental appendix.

Overall, we included a total of 25 journal articles, five National Policy Documents on National Strategic Health Development Plan, two National Policy on task shifting and task sharing of essential health services, two national guidelines on HIV testing and counselling, two reports on the presidential commission for Presidential Committee of Experts on Professional Relationships in the public health sector, five National Industrial Court judgements and one Act of Parliament establishing/reconstituting boards of University Teaching Hospitals. 


\section{Data charting}

Guided by our key concepts, we developed data charting form in Excel and extracted the following information: general study information, study year, cadres of health workers discussed, nature of boundary work and contextual factors around professional interaction, and reported outcomes of boundary work engaged in by different health professions (table 3).

\section{Collating, summarising and reporting the results}

To guide the analysis of the data, we drew on some theories and concepts from the fields of interprofessional care and social theory.

\section{Analytical framework}

Borrowing from the field of interprofessional care, we conducted a thematic analysis using Nancarrow and Borthwick's typology (earlier described) of the different directions that role-boundary shifts have occurred between health professions. Also, we used the theories of Medical dominance and Negotiated order ${ }^{27-29}$ which have been influential in the sociology of professions literature to offer explanations of the power dynamics and conditions that facilitated or constrained interprofessional collaboration in observed role-boundary shifts.

\section{Patient and public involvement}

It was not possible nor appropriate to conduct a patient and public involvement for this study.

\section{RESULTS}

This section contains a historical construction of the role-boundary dynamics related to health professions in Nigeria. We acknowledge the difficulty in capturing the full range of examples to illustrate each dynamic as it has evolved. While we note the possible gaps in our historical reconstruction, we made possible inferences from the interpretation of the available data.

In what follows, we adapted Nancarrow and Borthwick's typology to construct a historical account of the four directions in which role-boundary shifts have occurred between health professions in Nigeria, using the lens of the medical dominance and negotiated order theories. See table 3.

\section{Vertical substitution}

This refers to the transference of tasks across different health professions that are not equivalent in terms of training, expertise, power or autonomy. ${ }^{38}$ Early accounts of such transference date back to 1966 when the insertion of intra-uterine contraceptive device (IUCD) was the exclusive preserve of specialist doctors in Nigeria. ${ }^{53}$ To ward off the growing popularity and preference for nurses for IUCD insertion-a preference which also had the advantage of expanding coverage-doctors made a case for the acquisition of high-status roles and skills in maternal contraceptive services while discarding or delegating the less desirable task of IUCD insertion to nurses.
In this arrangement, doctors reserved for themselves only selected or complicated cases, while task-shifting routine IUCD insertion to nurses. ${ }^{54}$ The enhanced position of nurses through vertical encroachment of clinical roles made for an acceptable middle ground in which role boundaries were shifted without upsetting the balance of power. The tactics engaged by the medical profession was described by Larkin as 'occupational imperialism' in which professions advance themselves by acquiring higher status roles while delegating less wanted or 'dirtywork' to lower professions. ${ }^{53} 556$ We found other examples of similar work-boundary tactics deployed up until the early $1970 \mathrm{~s}$ for under-five children medical services. ${ }^{57}$ In all these cases we found, the medical profession was at the forefront of generating and disseminating evidence about the feasibility of task-shifting roles to nurses, including to what extent delegation should go and formalisation into operational guidelines.

Widespread national policy support for task-shifting in the context of vertical programmes from the 1990s brought about many cases of trans-disciplinary transference of tasks, partially driven by the need to integrate vertical disease programmes. Examples include doctornurses delegation of drug prescribing right for HIV care, nurse-community health extension worker (CHEW) delegation of long-acting family planning services (implants and IUCD insertion), and the midwife-CHEW delegation of maternal, newborn and child care services. ${ }^{58}$ In all these instances, the more powerful professions were all in charge of the process, paving the way for interprofessional consensus and non-conflictual role-boundary changes.

We noted instances of non-negotiation or highly conflictual cases of vertical boundary encroachment of professional jurisdictions. An example that saw significant power change and role shifts were the conflicts between pathologists and medical laboratory scientists between 2012 and 2014 over professional autonomy and regulation of medical laboratory services. The conflict related to an ambiguity between the contents of the parliamentary laws for the regulation and operation of clinical laboratory practice in Nigeria (Nigeria Medical and Dental Practitioners Act 1992 (as amended) and the Medical Laboratory Science of Nigeria Act 11 of 2003). Before this period, the medical profession had been the de facto regulator of medical laboratory services, a position which came under threat from tension caused by market advances in medical technology and the growing influence of medical laboratory practice. A final resolve to litigation (Suit no: NICN/Abj/128/2012-Association of Medical Laboratory Scientists of Nigeria \& two others vs Hon. Attorney General of the Federation and Minister of Justice \& five others-Judgement delivered on 23 Oct 2013) ${ }^{59}$ followed unsuccessful interventions by the Federal Ministry of Health. Legal outcomes gave control to the Medical Laboratory profession and established full autonomy for the profession within the clinical workspace. ${ }^{60}$ This example demonstrates how technological 


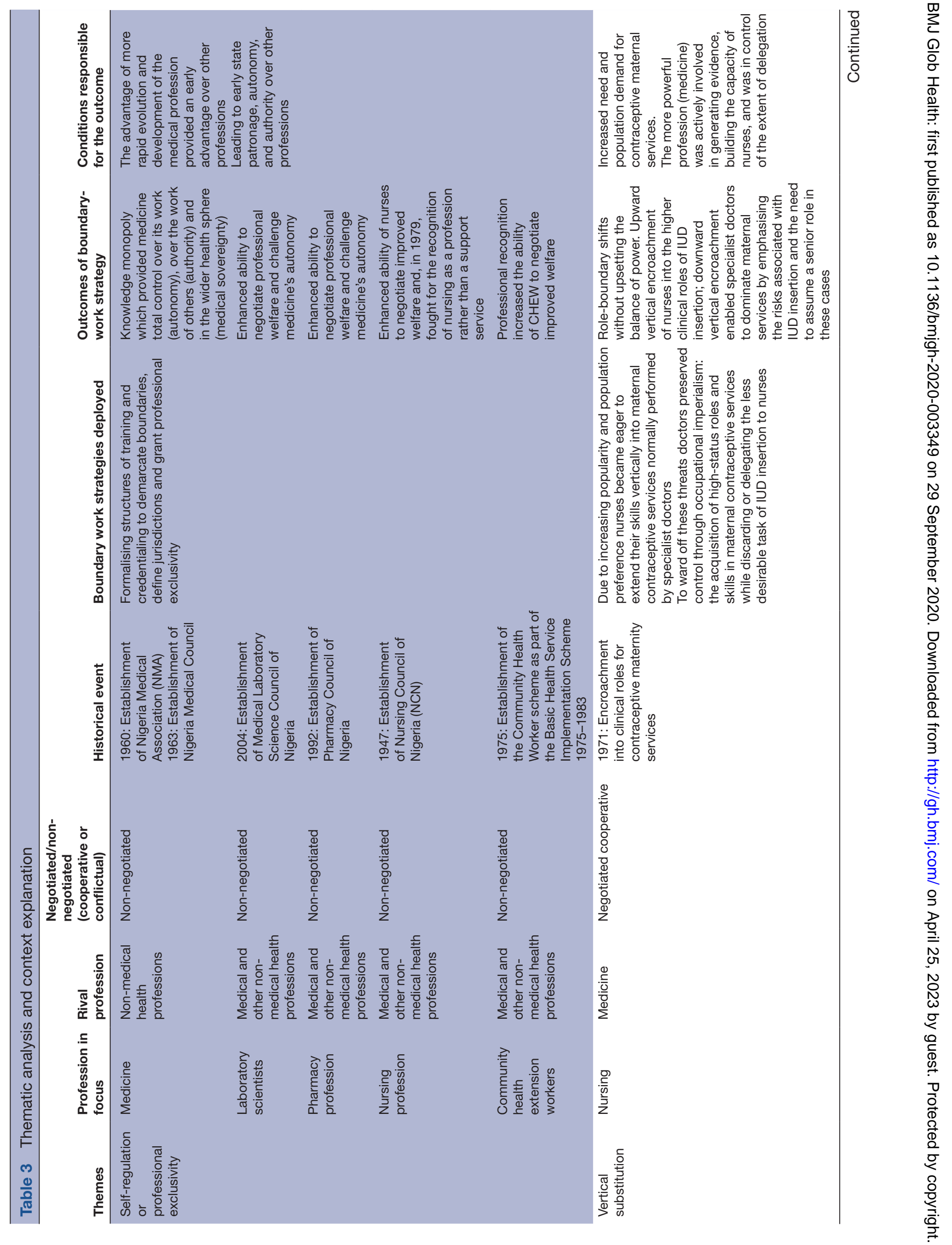




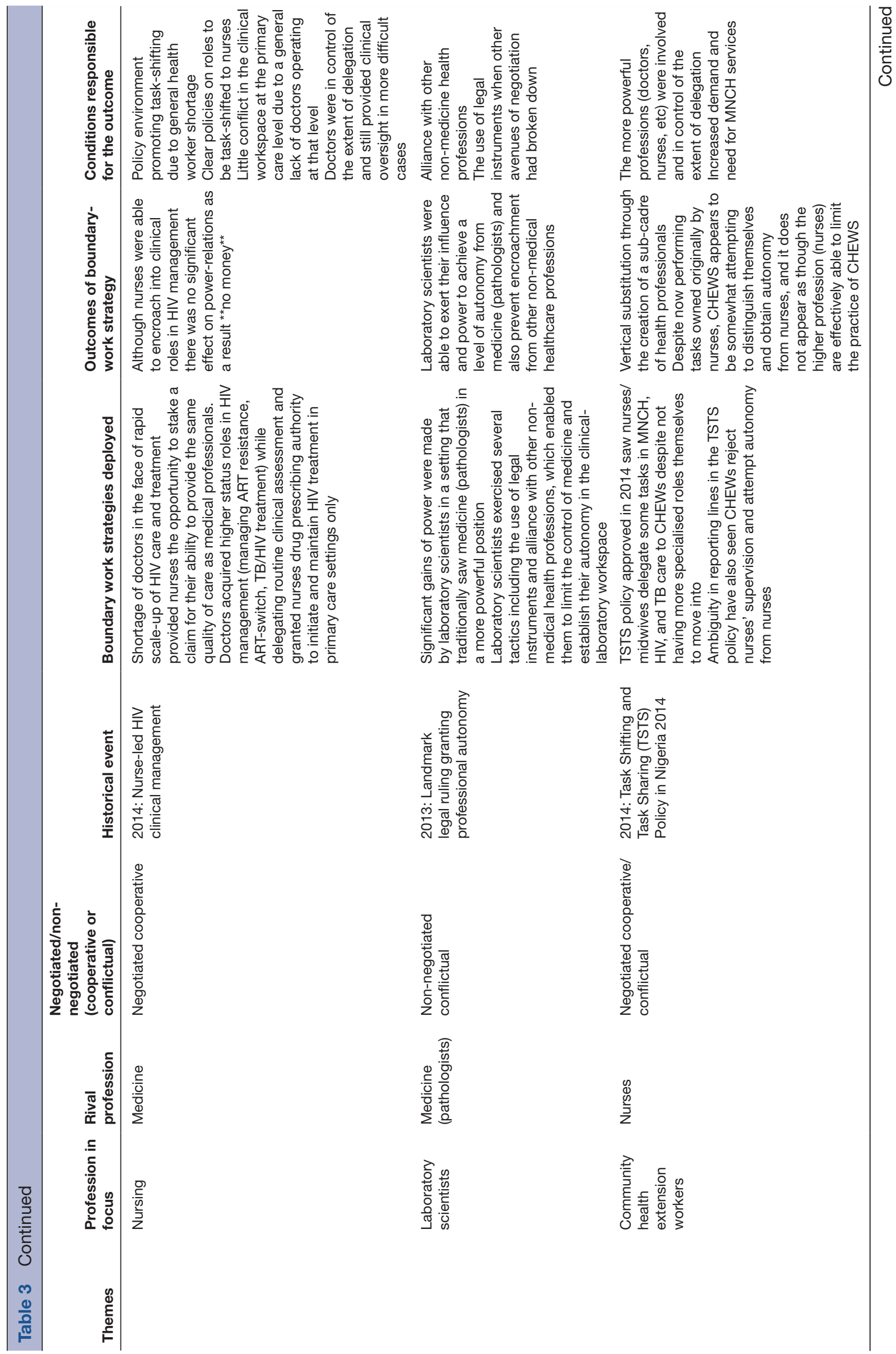




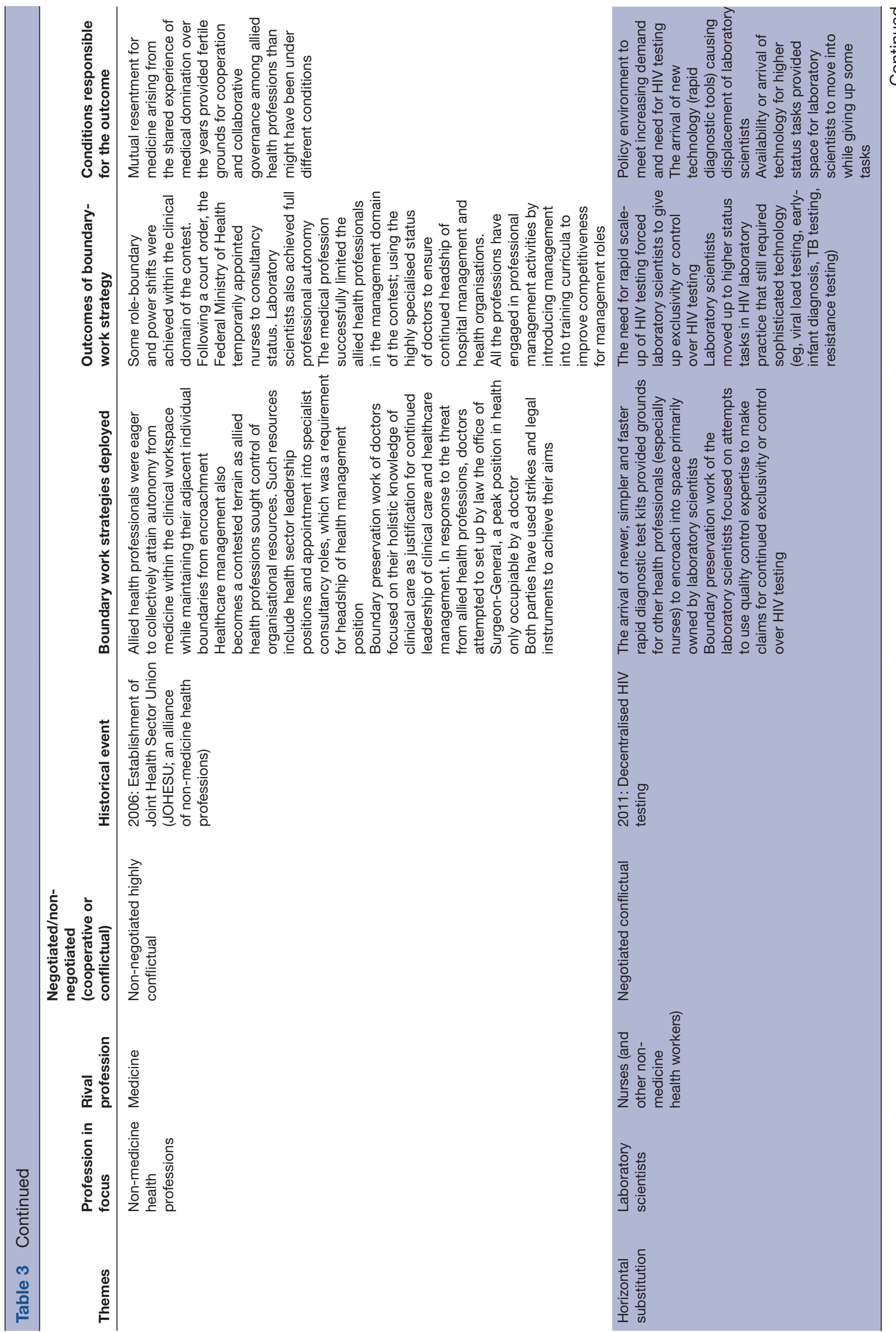




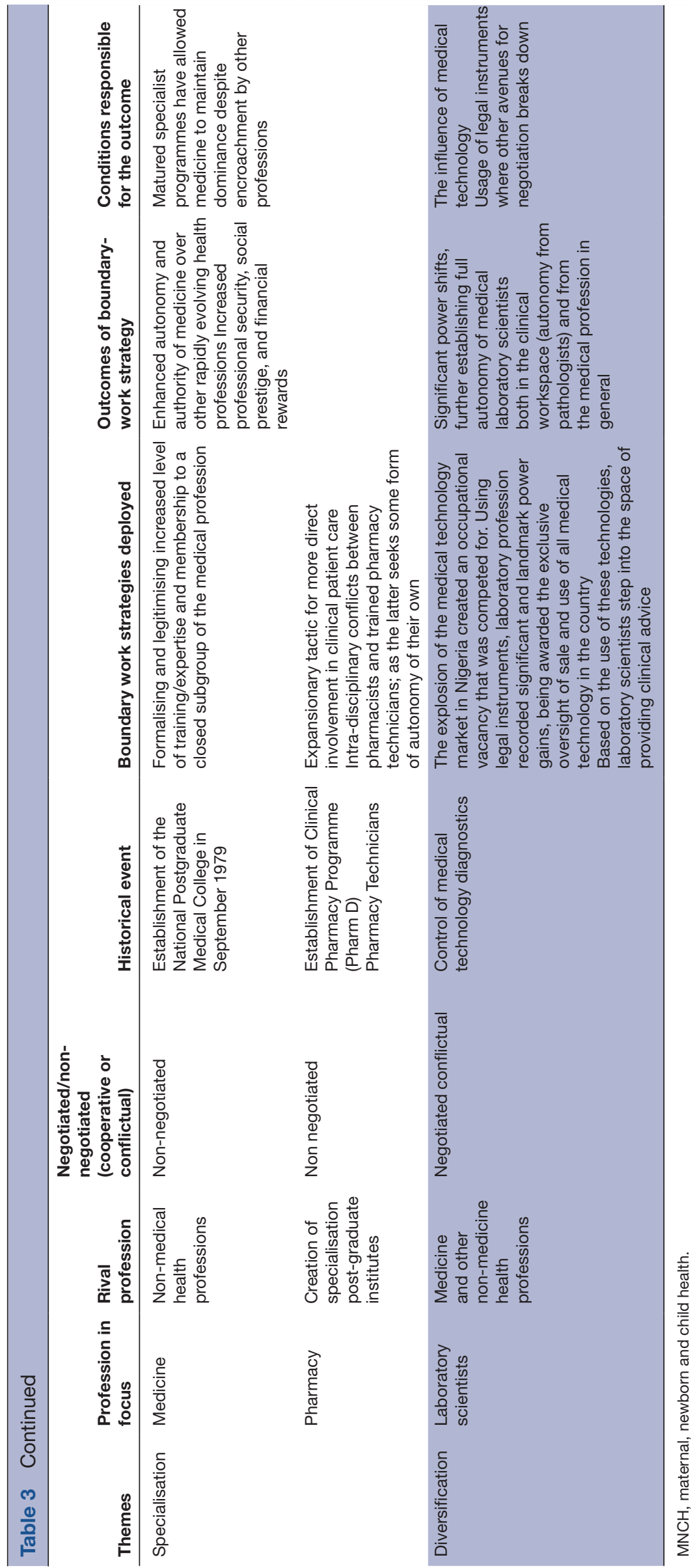


advances facilitated role-boundary shifts that undermined the power of medicine while opening up opportunities for a rival profession.

\section{Specialisation}

Specialisation occurs with the "adoption of an increasing level of expertise in a specific disciplinary area that is adopted by a select group of the profession and legitimised through the use of a specific title, membership to a closed-subgroup of the profession, and generally, involves specific training". ${ }^{38} \mathrm{Up}$ until recent years, clinical specialisation has been almost exclusive to the medical profession and has been used to great effect to strengthen its dominance in other areas. The more rapid evolution of medicine was due in part to the relatively early establishment of the medical education system. The National Postgraduate Medical College was formed in 1979 "as the tertiary institution at the apex of Medical Education in Nigeria and its main function is to produce specialists in all branches of Medicine and Dentistry". ${ }^{61}$ The college is backed by federal law and constitutes/trains a large proportion of doctors within the government health sector. The training is government-funded and backed by federal law (National Postgraduate Medical College Decree No. 67 of 24th September 1979, now Cap N59 Laws of the Federation 2004) making resident doctors a large proportion of all doctors working within the government health sector. The centrality of doctors to health policy process ${ }^{47}$ bestows the ability to get concessions from government more than any other profession within the health sector, a notable one being that only specialists (consultants) were allowed to hold clinical leadership and management positions. ${ }^{4362}$

The consultant status being the preserve of the medical profession over the years meant exclusive access to clinical and managerial leadership positions, which maintained the medical profession's advantage in the balance of power between the professions involved in healthcare. ${ }^{6364}$ However, this shared experience of clinical and managerial domination by the medical profession provided grounds for cooperation and collaborative governance (alliance-building) among all other health professions. The result was the formation in 2006 of a distinct organisational entity of allied health professionals from almost all other individual health professional associations outside of the medical profession, called the Joint Health Sector Union (JOHESU) ${ }^{64}$ The new entity had an overarching aim of challenging medical dominance. Within this allied health identity, individual professions maintained and protected their adjacent clinical work jurisdictions while simultaneously using the new identity to challenge medical dominance at the managerial domain of influence.

An example of highly conflictual role-boundary change that bordered on specialisation was the doctornurse conflict over the conferment of 'consultancy' status to other professions besides medicine. Given that specialisation was the gateway to holding clinical and management leadership position, contest over the meaning and eligibility to be a specialist ('consultant') became a hotly contested issue and a central issue that informed the setting up of two presidential committees to achieve "harmonious relationship amongst health workers and professional groups in the health sector". ${ }^{656}$ The allied health professionals engaged many tactics to redefine the meaning of 'consultant' status, including the use of health worker strikes, politicking and control of media narrative to propagate calls for 'autonomy and liberation from medical oppression'. ${ }^{24}$ The strategies ultimately culminated in a temporary legal victory in which consultant status was no longer exclusive to medicine. The Federal Ministry of Health, following a National Industrial Court judgement (the case between JOHESU vs Federal Ministry of Health, date), ${ }^{67}$ directed hospitals to confer and recognise specialist status (consultancy) for nurses, effectively granting nurses the eligibility to hold clinical and management leadership positions. ${ }^{68}$ The response of the medical profession to this development was to engage in industrial strikes to press for the creation of the office of a Surgeon-General (so far unsuccessful), to reserve by law a peak position in the health sector that can only be held by medical doctors. ${ }^{69}$ The perceived unwillingness of the medical profession to correct itself amidst highly publicised cases of management failures of doctor-managers of the health system was contributory to the new interest in healthcare management among healthcare professions in Nigeria. We found evidence of professions now incorporating management courses into professional training and education ${ }^{70}$ as a means to contest control of management jurisdictions.

\section{Horizontal substitution}

Horizontal substitution occurs when "providers with a similar level of training and expertise, but from different disciplinary backgrounds, undertake roles that are normally the domain of another discipline". ${ }^{38}$ The most notable account of horizontal substitution in Nigeria was within the context of HIV testing. The earliest national HIV testing guidelines had created a status hierarchy around HIV testing that had laboratory personnel at the top, conducting and supervising all aspects of HIV tests. ${ }^{72}$ Urgent national need to expand access to HIV services required significant decentralisation and task-shifting of HIV testing and task-shifting of HIV testing to nonlaboratory healthcare providers. As might be expected, task-shifting efforts met with initial resistance from Medical Laboratory Scientists that was only resolved as more sophisticated laboratory technology tasks for HIV care became available (eg, early-infant diagnosis, viral load testing, etc) became available. ${ }^{73}$

This willingness of Medical Laboratory Scientists to let go of HIV testing to non-laboratory healthcare providers to expand to new niches is in keeping with the theory of negotiated order in which the willingness to let go of particular tasks depends on the availability of other types of work to occupy. Concurrent events that facilitated 
this horizontal blurring of boundaries was the coming together of individual healthcare professions to form JOHESU as a strategic resource to gain clinical and managerial autonomy from medicine. Mutual interest against a common dominant profession made alliance the best option or only recourse to the medical profession. In this sense, the conventional meaning of individual professions as being 'allied to medicine' had switched to that of being 'allied to each other', and it was in this context that collaborative governance became more possible than it might have been. ${ }^{74}$

\section{Diversification}

Diversification refers to the identification of a novel approach to practice that has previously not been 'owned' by a particular disciplinary group, resulting in the expansion of the role for that discipline. Diversification is different from specialisation in that while specialisation involves expertise in a specific area within a discipline, tasks created through diversification are available to all members of that profession. ${ }^{38}$ As already described, the legitimation of the medical laboratory profession as the regulator of medical diagnostics, a role previously held by the medical profession, has seen medical laboratory practice expand beyond standard laboratory practice. This expansion is also now driving sub-specialisation within the medical laboratory profession.

\section{DISCUSSION}

Persistent health professional conflicts due to roleboundary disputes are likely to undermine collaborative care and the ability of the health workforce to meet healthcare needs in line with stated policy objectives. With implications as important as rising costs due to rising costs of care, ${ }^{15}$ to severe disruption to health services, ${ }^{62}$ health workforce governance must be more informed of power processes underlying or mediating professional interdependencies. Our study provides valuable insights on this by drawing on illustrative accounts of interprofessional power change and role-boundary dynamics in Nigeria. The notion of health professions being engaged in constant negotiation, within an overall structure of medical dominance, appears to be supported by our account, suggesting that applied medical dominance and negotiated order theories are complementary.

Role-boundary negotiation through vertical substitution appears to be more hotly contested than other types of mechanisms given the instances of litigation. This may indicate an inherent difficulty in negotiating roleboundary changes between professions at different power gradients. However, our examples suggest that consensually negotiated vertical substitution is also possible and is likely to occur when all the professions involved in negotiation are more likely to benefit through a simultaneous upward expansion of their current roles. ${ }^{38}$ Specific to the Nigerian context, the lack of new areas of work for the medical profession, despite its comparative specialised status, may hamper the ability to delegate aspects of their work and predispose to more interprofessional conflicts in the future, if other health professions evolve faster with the advantages afforded by new technology.

The stalled evolution of medicine in Nigeria may also explain the increasing brain drain among doctors to either private practice or more medically advanced countries. Our explanation agrees with that of Nancarrow and Borthwick $^{38}$ that the assumption underlying current taskshifting policies that existing professions have a desire to delegate work and expand their boundaries may not always be true or possible for all professions. In our example involving initial resistance to task shifting of HIV testing, laboratory scientists perceived delegation of HIV testing as devaluing the high standard of quality control held by their profession, rather than as an opportunity to delegate the unwanted or basic tasks. The resistance was tempered in part by the arrival of more sophisticated laboratory tasks in HIV services (eg, DNA PCR testing, Early Infant Diagnosis testing, resistance testing, haematological, electrolyte and urea tests in HIV management) showing that regardless of how well intentioned a taskshifting policy is, professions can only expand when there is room for expansion.

Notably, we found that vertical substitution is more likely to be consensual in instances where the more powerful profession was involved and in control of the extent of delegation. We saw this with the doctor-nurse IUD task-shifting and also noted that most of the advocacies and course content development for CHEWS training towards task-shifting are being led by nurses/ midwives. We also found scenarios of workforce shifts that show how boundary struggles can cause system disturbances or disequilibria that can propagate widely such that as a profession was displaced from one jurisdiction of work, it in return, invaded a more lucrative jurisdiction. Examples include vertical substitution involving doctor-nurse IUD insertion, horizontal substitution involving laboratory scientists and other nonmedicine professions, the displacement of nurses from lower tasks by CHEWS, and their subsequent expansion into more lucrative clinical jurisdictions to become nurse consultants.

We also note that financial considerations are important for role-boundary shifts and can influence the pace of reforms. Despite the enactment of task-shifting policies encouraging an upward expansion of roles, we noted little uptake in instances where such role-expansion is not tied to financial rewards, for example, the nurse-led management of clinical care in ART settings. Such role changes were also more likely to be consensual, but in some instances, we found threats of industrial action from feelings of frustration, stress and burnout due to additional responsibilities for the expanding profession. ${ }^{75}$ In contrast, improved financial rewards associated with specialisation (eg, specialist allowances) appear to be a significant incentive for conflictual encroachment of nurses and pharmacists into traditional clinical roles. 
Our findings on the circumstances in which roles and tasks are readily ceded carry important implications for task shifting policies that come with the introduction of new cadres, for example, community health workers. Given that professions are in constant negotiation with one another, whatever gains may be achieved with the introduction of new cadres could quickly give way to more amplified role-boundary conflicts due to increased competing cadres, as we found in instances of community health workers (CHEWs) rejecting direct nursing supervision of shifted tasks that were owned originally by the nursing profession. ${ }^{76}$ Under these circumstances, the wage differential between professions can serve as the trigger for unending strikes, escalating wages and cost inefficiencies as professions challenge perceived power imbalances manifesting as inequitable financial remuneration. While it is clear that strikes by health professions in Nigeria have resulted in increases in wages across professional groups, wage disputes remain largely unresolved. Such unintended consequences can be avoided if task-shifting policies in their design consider potential implications from contextual power dynamics between existing professions. Task shifting policies need to have a systemic view on the cascade of potential reactions, and need to build scenarios and be forward-thinking as there are unexpected consequences. This is particularly relevant to ongoing attempts ${ }^{77}$ at reforming provider payment mechanisms, with important implications for collaborative work and quality of care. For example, feefor-service payment mechanisms may make it difficult to shift tasks away from medical professionals in cases where they may lose income as a result. Capitation payments may encourage task shifting, and this may lead to reduced quality of care unless accompanied by regulatory oversight and professional accountability.

Our study also calls attention to the evolving relationship between management and healthcare, a relationship that has been well analysed in the literature. In contrast to HICs like the UK and Australia where the introduction of New Public Management strategies presented significant challenges to the power and autonomy of the medical profession, ${ }^{48}$ management in Nigeria has been used as a resource to preserve and perpetuate medical dominance. In contrast to Australia where top-down management reform of health services led to the emergence and enhanced position of allied health professions relative to medicine, ${ }^{74}$ allied healthcare in Nigeria appears to be a bottom-up realignment of professional powers to force management reform of health services. Either way, broader changes in health system governance through public management as a driver of change (as in Australia) or as an incentive for change (as in Nigeria) will be mediated by interprofessional relations. Professional conflicts in this sense can have important implications for the way health system governance is implemented and the kinds of services that are ultimately delivered. ${ }^{78}$

Some of these tensions have been the result of the agency of health professionals acting in their interest.
However, we noted how outside forces like technology act as triggers and play important roles in simultaneously opening domains of practice while closing others. We showed for example how the introduction of new types of medical diagnostic technology caused an important power shift between doctors and laboratory scientists. However, in countries where health workforce governance and management depend on health professionals themselves rather than specialist managers, health management (as an incentive for a change) may become an increasingly contested jurisdiction of work with huge implications for service delivery. We found evidence of ongoing re-stratification across Nigerian health professions, as management is gradually incorporated into professional training curricula, with potential for greater tension in the future.

Our study makes an important conceptual and methodological contribution to the topic of interprofessional relations, especially in LMIC. By combining perspectives from the fields of social theory, interprofessional care and health services, our approach informed a deeper examination of interprofessional relations in Nigeria, at a time when the country is experiencing its worst crisis in health workforce governance. Although Nancarrow and Borthwick's framework was constructed from within the Anglo/ North American context, it permitted an account of the full range of boundary changes we observed in Nigeria. The use of historical analysis also allowed us to approach the topic in a way that cannot be approached by more common methods like surveys, interviews and crosssectional studies. While we used the theories of medical dominance and negotiated order to explore factors shaping interprofessional interactions at the macrostructural and meso-structural levels, our approach did not permit us to explore the interplay of factors between these levels and the micro level, which represent the focus of most studies on interprofessional relations in LMICs. The frameworks by Reeves $e t a l^{79-81}$ provide a useful framework in this regard, allowing for direct comparison of interprofessional interactions, interventions and outcomes across a range of macro, meso and micro levels.

Evolving tensions and re-definition of roles present further fertile grounds for global health researchers. An important line of inquiry may be a comparative analysis of professional resistance and conflict and instances of collaborative governance based on mutual interests, or a comparative analysis of health systems where all health professions have varying opportunities to contest various clinical and management jurisdictions, and the lessons from such contests. Under what conditions do members of a health profession or groups of professions mobilise, organise or build consensus? And under what circumstances do such consensus fail or succeed? What is the relative impact of their failure or success on health system performance and outcomes? Researchers may also seek to understand how interprofessional conflicts affect health priorities within national or local health systems and the quality of services delivered. 
To do this, global health and health systems research will have to shift from a focus on political power in high places, and instead (or in addition) concentrate on efforts to help health systems navigate the swampy lowland of professional rivalry and power.

\section{Author affiliations}

${ }^{1}$ Department of Public Health, Institute of Tropical Medicine, Antwerp, Antwerpen, Belgium

${ }^{2}$ HIV and Viral Hepatitis Unit, United Nations Volunteer, WHO Nigeria, Abuja, Nigeria ${ }^{3}$ School of Public Health, University of Sydney, Sydney, New South Wales, Australia

Twitter Okikiolu Badejo @badejokikiolu and Helen Sagay @heltisa

Acknowledgements The authors acknowledge support from the Emerging Voices for Global Health (EV4GH) in refining the ideas presented in this paper at the 5th Global Symposium on Health Systems Research, Liverpool 2018. We also thank Clara Affun-Adegbulu for reviewing earlier drafts of this paper.

Contributors $\mathrm{OB}$ conceived the study and wrote the first draft. $\mathrm{OB}$ and $\mathrm{HS}$ conducted the literature search and analysis. SA and SVB provided critical reviews of all draft versions; all authors revised and approved the final draft.

Funding The authors have not declared a specific grant for this research from any funding agency in the public, commercial or not-for-profit sectors.

Competing interests None declared.

Patient and public involvement Patients and/or the public were not involved in the design, or conduct, or reporting, or dissemination plans of this research.

Patient consent for publication Not required.

Provenance and peer review Not commissioned; externally peer reviewed.

Data availability statement Data sharing not applicable as no datasets generated and/or analysed for this study. This study was a review of documents that were publicly available or obtainable.

Open access This is an open access article distributed in accordance with the Creative Commons Attribution Non Commercial (CC BY-NC 4.0) license, which permits others to distribute, remix, adapt, build upon this work non-commercially, and license their derivative works on different terms, provided the original work is properly cited, appropriate credit is given, any changes made indicated, and the use is non-commercial. See: http://creativecommons.org/licenses/by-nc/4.0/.

\section{ORCID iDs}

Okikiolu Badejo http://orcid.org/0000-0002-8124-7018

Helen Sagay http://orcid.org/0000-0002-2866-8112

Seye Abimbola http://orcid.org/0000-0003-1294-3850

Sara Van Belle http://orcid.org/0000-0003-2074-0359

\section{REFERENCES}

1 van de Pas R, Kolie D, Delamou A, et al. Health workforce development and retention in Guinea: a policy analysis post-Ebola Hum Resour Health 2019;17:63.

2 Scheffler R, Cometto G, Tulenko K, et al. Health workforce requirements for universal health coverage and the sustainable development goals. Geneva: World Health Organization, 2016. https://apps.who.int/iris/bitstream/handle/10665/250330/ 9789241511407-eng.pdf?sequence $=1$

3 van GE, Schäfer W, Kroneman M. Managed competition in the Netherlands: an example for others? Eurohealth 2010;16:23-6.

4 Boyce RA. Health sector reform and professional power, autonomy and culture: the case of Australian allied health professions. In: Concepts of care. Developments in health \& social welfare. London, England: Edward Arnold, 1997: 74-88. https://www.researchgate. net/publication/45165981_Health_sector_reform_and_professional_ power_autonomy_and_culture_The_case_of_Australian_allied health professions

5 Douven R, Katona K, T Schut F, et al. Switching gains and health plan price elasticities: 20 years of managed competition reforms in The Netherlands. Eur J Health Econ 2017;18:1047-64.

6 Kuhlmann E, Burau V, Correia T, et al. "A manager in the minds of doctors": a comparison of new modes of control in European hospitals. BMC Health Serv Res 2013;13:246.
7 Douven R, Burger M, Schut F. Does managed competition constrain hospitals' contract prices? Evidence from the Netherlands. Health Econ Policy Law 2019:1-14

8 Kuhlmann E, Batenburg R, Dussault G. Where health workforce governance research meets health services management. Health Serv Manage Res 2016;29:21-4.

9 Germov J. Managerialism in the Australian public health sector: towards the hyper-rationalisation of professional bureaucracies. Sociol Health IIIn 2005;27:738-58.

10 Larkin GV. Medical dominance in Britain: image and historical reality. Milbank Q 1988;66(Suppl 2):117-32.

11 Allsop J. Medical dominance in a changing world: the UK case. Health Sociol Rev 2006;15:444-57.

12 Willis E. Introduction: taking stock of medical dominance. Health Sociol Rev 2006;15:421-31.

13 Callaghan M, Ford N, Schneider H. A systematic review of taskshifting for HIV treatment and care in Africa. Hum Resour Health 2010;8:8.

14 Fulton BD, Scheffler RM, Sparkes SP, et al. Health workforce skil mix and task shifting in low income countries: a review of recent evidence. Hum Resour Health 2011;9:1.

15 Nancarrow SA. Six principles to enhance health workforce flexibility. Hum Resour Health 2015;13:9.

16 Galukande M, Kaggwa S, Sekimpi P, et al. Use of surgical task shifting to scale up essential surgical services: a feasibility analysis at facility level in Uganda. BMC Health Serv Res 2013;13:292.

17 Okyere E, Mwanri L, Ward P. Is task-shifting a solution to the health workers' shortage in northern Ghana? PLoS One 2017;12:e0174631.

18 De Brouwere V, Dieng T, Diadhiou M, et al. Task shifting for emergency obstetric surgery in district hospitals in Senegal. Reprod Health Matters 2009;17:32-44.

19 Luboga S, Macfarlane SB, von Schreeb J, et al. Increasing access to surgical services in sub-Saharan Africa: priorities for national and international agencies recommended by the Bellagio Essential Surgery Group. PLoS Med 2009;6:e1000200.

20 World Health Organization. Task shifting: rational redistribution of tasks among health workforce teams: global recommendations and guidelines, 2008.

21 Wilsford D. Doctors and the state: the politics of health care in France and the United States. Duke University Press, 1991.

22 Mechanic D. Some dilemmas in health care policy. Milbank Mem Fund Q Health Soc 1981;59:1-15.

23 King O, Nancarrow SA, Borthwick AM, et al. Contested professional role boundaries in health care: a systematic review of the literature. J Foot Ankle Res 2015;8:2.

24 Adeloye D, David RA, Olaogun AA, et al. Health workforce and governance: the crisis in Nigeria. Hum Resour Health 2017;15:32.

25 Irimu G, Ogero M, Mbevi G, et al. Tackling health professionals strikes: an essential part of health system strengthening in Kenya. BMJ Glob Health 2018;3:e001136.

26 Kirkpatrick I, Dent M, Jespersen PK. The contested terrain of hospital management: professional projects and healthcare reforms in Denmark. Current Sociology 2011;59:489-506.

27 Nugus P, Greenfield D, Travaglia J, et al. How and where clinicians exercise power: interprofessional relations in health care. Soc Sci Med 2010;71:898-909.

28 Willis E. Medical dominance: the division of labour in Australian health care. Allen \& Unwin, 1989. https://books.google.be/books? id=Sh5wHQAACAA $J$

29 Fine GA. Negotiated orders and organizational cultures. Annu Rev Sociol 1984;10:239-62.

30 Light $\mathrm{D}$, Levine $\mathrm{S}$. The changing character of the medical profession: a theoretical overview. Milbank Q 1988;66(Suppl 2):10-32.

31 Navarro V. Professional dominance or proletarianization?: neither. Milbank Q 1988;66(Suppl 2):57-75.

32 Friedson E. The reorganization of the medical profession. Med Care Rev 1985;42:11-35.

33 Broom A. Reflections on the centrality of power in medical sociology: an empirical test and theoretical elaboration. Health Sociol Rev 2006;15:496-505

34 Timmermans S, Kolker ES. Evidence-based medicine and the reconfiguration of medical knowledge. J Health Soc Behav 2004:45(Suppl):177-93.

35 Allen D. The nursing-medical boundary: a negotiated order? Sociol Health IIIn 2008;19:498-520.

36 Farberman HA. A review symposium: Anselm L. StraussNegotiations: varieties, contexts, processes, and social order San Francisco: Jossey-Bass, 1978. Symb Interact 1979;2:153-68.

37 Copp M. Negotiated order. In: Encyclopedia of social theory. Thousand Oaks, California, United States: SAGE Publications, Inc, 2005. 
38 Nancarrow SA, Borthwick AM. Dynamic professional boundaries in the healthcare workforce. Sociol Health IIIn 2005;27:897-919.

39 Browne SG. A history of the Nigerian health services. Med Hist 1973;17:435-6.

40 Scott-Emuakpor A. The evolution of health care systems in Nigeria: which way forward in the twenty-first century. Niger Med $J$ 2010;51:53-65.

41 Nigeria Medical Association (NMA). History of the Nigerian Medical Association. Available: https://nationalnma.org/about/ [Accessed 7 Jun 2020].

42 Medical and Dental Council of Nigeria (MDCN). MDCN Mandate - Mission and Vision. Available: https://www.mdcn.gov.ng/page/ about-us/mden-mandate-mission-vission [Accessed 7 Jun 2020].

43 Ogoh Alubo S. Power and privileges in medical care: an analysis of medical services in post-colonial Nigeria. Soc Sci Med 1987;24:453-62.

44 Ajibade BL. Nursing in Nigeria, the journey so far and way forward. Nursing World Niger. Available: http://www.nursingworldnigeria.com/ 2013/02/nursing-in-nigeria-the-journey-so-far-and-way-forward-b-Iajibade-rn-ph-d-fwacn [Accessed 7 Jun 2020].

45 Our History. Medical Laboratory Science Council of Nigeria. Available: http://web.mlscn.gov.ng/index.php/our-history/ [Accessed 7 Jun 2020].

46 Pharmacists Council of Nigeria. About us: brief history. Available: https://www.pcn.gov.ng/about-us/ [Accessed 7 Jun 2020].

47 Alubo SO. The medical profession and health policy in Nigeria, 1994.

48 Arksey H, O'Malley L. Scoping studies: towards a methodological framework. Int J Soc Res Methodol 2005;8:19-32.

49 Freidson E. Professional dominance: the social structure of medical care. Atherton Press, 1970. Available: https://vpn.uantwerpen. be?url=https\%3a\%2f\%2fsearch.ebscohost.com\%2flogin.aspx\% 3fdirect\%3dtrue\%26AuthType\%3dip\%2curl\%2cuid\%26db\% 3dcat01187a\%26AN\%3dABC.c.lvd.11409\%26site\%3deds-live

50 Abrams R, VANDREVALA T, SAMSI K, et al. The need for flexibility when negotiating professional boundaries in the context of home care, dementia and end of life. Ageing Soc 2019;39:1976-95.

51 Scott J. A matter of record: documentary sources in social research. Polity, 1990. Available: https://vpn.uantwerpen.be?url=https\%3a\% 2f\%2fsearch.ebscohost.com\%2flogin.aspx\%3fdirect\%3dtrue\% 26AuthType\%3dip\%2curl\%2cuid\%26db\%3dcat01187a\%26AN\% 3dABC.c.Ivd.519811\%26site\%3deds-live

52 Tyndall J. AACODS checklist for appraising grey literature, 2010. Available: https://dspace.flinders.edu.au/xmlui/bitstream/handle/ 2328/3326/AACODS_Checklist.pdf;jsessionid=BCED5F0D8262715E 7CCB904E34BDF667? sequence $=4$ [Accessed 8 Aug 2020].

53 Hartfield VJ. The role of the nurse in a family planning programme. Contraception 1971;3:105-14.

54 Reeves S, Rice K, Conn LG, et al. Interprofessional interaction, negotiation and non-negotiation on general internal medicine wards. $J$ Interprof Care 2009;23:633-45.

55 Hartfield VJ. The role of paramedical personnel in family planning programmes - with particular reference to intra-uterine devices. West Afr Med J Niger Pract 1968;17:225-6.

56 Hartfield VJ. Experience with the Lippes loop in a provincial hospital. West Afr Med J Niger Pract 1969;18:125-35.

57 Morley D. A medical service for children under five years of age in West Africa. Trans R Soc Trop Med Hyg 1963;57:79-88.

58 Federal Ministry of Health (FMOH). Task-shifting and task-sharing policy for essential health care services in Nigeria, 2014. Available: https://advancefamilyplanning.org/sites/default/files/resources/ Nigeria\%20taskshifting\%20policy-Aug2014\%20REVISEDCLEAN\% 20_Approved\%200ctober\%202014.pdf

59 National Industrial Court Judgement Portal. Incorporated Trustees of Association of Medical Laboratory Scientists of Nigeria (AMLSN) \& 2 ORS -VS- Honourable Attorney General of the Federation and Minister of Justice, Federal Ministry of Justice, Abuja \& 5 ORS::NICN-JUDGEMENT PORTAL. Judgement Portal. Available: https://www.nicnadr.gov.ng/judgement/details.php?id=1615 [Accessed 28 Jun 2020].

60 Medical World Nigeria. National industrial court: laboratory scientists should practise without direction from a medical doctor. Available: https://medicalworldnigeria.com/post/national-industrial-court-labscientists-should-practise-without-direction-from-a-medical-doctor? pid=20780 [Accessed 7 Jun 2020].
61 National Postgraduate Medical College of Nigeria. Establishment and functions. Available: https://npmcn.edu.ng/about-us/ establishment-and-functions/ [Accessed 7 Jun 2020].

62 Alubo SO. The political economy of doctors' strikes in Nigeria: a Marxist interpretation. Soc Sci Med 1986;22:467-77.

63 Law Care Niger. University Teaching Hospitals Boards Act, 2019. Available: https://lawcarenigeria.com/university-teaching-hospitalsreconstitution-of-boards-act/ [Accessed 7 Jun 2020].

64 Alubo O, Hunduh V. Medical dominance and resistance in Nigeria's health care system. Int J Health Serv 2017;47:778-94.

65 Presidency. Presidential Committee (Justice Bello Gusau). Report of the Presidential Committee on the harmonious work relationship amongst health workers and professional groups in the health sector in Nigeria, 2011.

66 Presidency. Presidential Committee 2014 (Yayale Ahmed) of experts on Inter-professional relationship in the public health sector, 2014.

67 Nursing World Nigeria. National Industrial Court of Nigeria: ruling between JOHESU and the Federal Ministry of Health, 2013. Available: http://www.nursingworldnigeria.com/2014/9/nationalindustrial-court-of-nigeria-ruling-between-johesu-and-the-federalministry-of-health [Accessed 7 Jun 2020].

68 Federal Ministry of Health. Compliance with the judgement o(sic) the National Industrial Court of Nigeria on the appointment of nonmedical officers as consultants/payment of Specialist Allowance, MH/PM/138/Vol.111/78, 2014

69 Information Nigeria. Doctors' Strike: Jonathan Agrees To Appoint Nigeria's First Ever Surgeon-General, 2014. Available: https://www. informationng.com/2014/01/doctors-strike-jonathan-agrees-toappoint-nigerias-first-ever-surgeon-general.html [Accessed 7 Jun 2020]

70 Ojo TO, Akinwumi AF. Doctors as managers of healthcare resources in Nigeria: evolving roles and current challenges. Niger Med $J$ 2015;56:375.

71 Nursing and Midwifery Council of Nigeria. Memo: restructuring of the current post basic nursing clinical specialty into post-graduate programmes for the award of academic certificates. Available: https://nursingworldnigeria.com/files/files/NMCN\%20MEMO\% 20ON\%20RESTRUCTURING.pdf

72 Federal Ministry of Health (FMOH). National guidelines for HIV counselling and testing, 2011. Available: https://aidsfree.usaid.gov/ sites/default/files/hts_policy_nigeria.pdf

73 Ofem O, Jasper TL, Torbunde N, et al. Effect of task-shifting HIV testing from laboratory personnel to nurses on paediatric and adolescent HIV testing rate and yield in rural Nigeria: a prospective before-and-after study. Lancet Glob Health 2019;7:S23.

74 Boyce R. Emerging from the shadow of medicine: allied health as a 'profession community' subculture. Health Sociology Review 2006;15:520-34.

75 Lasebikan VO, Oyetunde MO. Burnout among nurses in a Nigerian general hospital: prevalence and associated factors. ISRN Nurs 2012;2012:1-6.

76 Task Shifting and Task Sharing: Understanding the Policy By Faruk Umar Abubakar Secretary General/Registrar NMCN Nursing World Nigeria - Nursing Jobs, Forum and News. Available: https://www. nursingworldnigeria.com/2019/05/task-shifting-and-task-sharingunderstanding-the-policy-by-faruk-umar-abubakar-secretarygeneral-registrar-nmcn [Accessed 3 Jun 2020].

77 Onoka CA, Hanson K, Hanefeld J. Towards universal coverage: a policy analysis of the development of the National health insurance scheme in Nigeria. Health Policy Plan 2015;30:1105-17.

78 van Rensburg AJ, Rau A, Fourie P, et al. Power and integrated health care: shifting from governance to governmentality. Int $J$ Integr Care 2016;16:17.

79 Reeves S, Hean S. Why we need theory to help us better understand the nature of interprofessional education, practice and care. $J$ Interprof Care 2013;27:1-3.

80 Reeves S, Goldman J, Gilbert J, et al. A scoping review to improve conceptual clarity of interprofessional interventions. J Interprof Care 2011;25:167-74.

81 A Conceptual Framework for Interprofessional Teamwork. Interprofessional teamwork for health and social care. John Wiley \& Sons, Ltd, 2010: 57-76. 